\title{
IN AN ERA OF SOCIAL, CIVIC AND POLITICAL DISENGAGEMENT, DO HEALTH CARE AND SOCIAL WELFARE PROTECTION STILL MATTER TO POPULATION HEALTH? EVIDENCE FROM OECD MORTALITY DATA ${ }^{1}$
}

\author{
ERNESTO R. FERREIRA ${ }^{1}$ - JOÃO D. MONTEIRO² \\ ${ }^{1}$ Department of Management and Economics, Faculty of Human and Social Sciences, \\ University of Beira Interior, Covilhã, Portugal \\ Email:ferreira@ubi.pt \\ ${ }^{2}$ Department of Management and Economics, Faculty of Human and Social Sciences, \\ University of Beira Interior, Covilhã, Portugal \\ Email:jdm@ubi.pt
}

\begin{abstract}
Have we reached the point where more spending on health care and other forms of social protection is not producing better health as measured by reductions in population mortality? Drawing on two decades of research and mortality statistics (1995-2015) for 17 OECD countries, our analysis confirms and builds on the observed relationship between the returns and investments in health and social welfare spending. First, the results suggest that there is a differential effect of socioeconomic, lifestyle and demography variables on total and cause-specific mortality rates. Second, the basic premise of an association between health care expenditure and mortality rates is reinforced in models that take into account public-only health expenditure and its impact on older age groups. Third, a strong protective effect of government-sponsored welfare expenditure on infant mortality was observed. This effect is weaker on other causes of death and suggests that older individuals, in this sample of developed countries, may have reached a stage of the epidemiological transition in which health improvement is indifferent to government assistance and depends largely on behavioural change.
\end{abstract}

Keywords: investments in health and welfare, cause-specific mortality

JEL-codes: I12, I18, I38 


\section{INTRODUCTION}

Health care has often been defined as a myriad of goods and services that maintain, improve, or restore a person's health (Santerre - Neun 2010). From the standpoint of economics, in most developed countries, the health care sector has become a key part of national economies and total expenditure, both as a percentage of gross domestic product (GDP) and on a per capita basis, and has increased significantly over the years. In 2017, the amount of health care spending per capita in the Organization for Economic Cooperation and Development (OECD) countries averaged 4,003 USD, and the ratio of total health care costs to GDP reached 8.9 percent (OECD 2018). According to the OECD, nearly three-quarters of the total investments in health came from public (state) sources and constituted the main health care financing arrangement in member states. The United States is estimated to have spent 17.2 percent of its GDP on health and 9,892 USD for each resident - far more than any other country studied and more than two-and-ahalf times the OECD-35 average. Mexico and Turkey were the lowest per capita spenders on health (1,080 USD and 1,088 USD, respectively). Yet the assessed health status of populations are not strongly related to the level of spending on health services, in that countries with similar levels of expenditure have different levels of health. For Example, Japan (83.9 years), Spain (83.0 years) and Switzerland (83.0 years) have the best overall health results in terms of life expectancy at birth, yet Switzerland spends more than twice as much on health per capita as Spain (7,919 USD and 3,248 USD, respectively). Likewise, the United States spends far more on health per capita in purchasing power parity than Turkey and the Czech Republic yet achieves about the same average level of life expectancy at birth (78.5 years). Clearly, as these numbers indicate, the financial inputs to health care are significant but are only one of a number of factors determining population health.

In this study, we aim to explore the specific issues raised by the literature concerning the wider relationship between health inputs and health. As indicators of health, we chose to use mortality rates because these are measures of health that are reliable, stable over time, and equivalent across settings. We note that these indicators may not fully capture all meaningful aspects of health, such as reduction in pain and other improvements in the quality of life, but these measures of health avoid potential biases inherent in self-assessed reports of health conditions. The underlying methodological approach to this study uses a fixed-effects estimator and an unbalanced panel data set that includes variables for 17 OECD countries between 1995 and 2015. In describing the process under study, our choice of methodology relies on evidence gathered by authors like Ferreira et al. (2018), Jaba et al. (2014) and, in particular, Schnittker and Karandinos (2010). 
In this vein, the paper proposes that the process underlying total and cause-specific mortality is a function of health spending and a host of other factors, including income growth, the urbanisation rate, the total fertility rate, alcohol consumption and a time variable to account for possible deterministic trends in the data. In addition, two public policy variables (namely, social welfare and health-specific expenditure) are included in our specifications to account for the financial effort made by national governments to address public health and social issues.

In brief, three important conclusions could be derived from the findings. First, the results suggest that there is a differential effect of socioeconomic, lifestyle and demography variables on total and cause-specific mortality rates. Second, the basic premise of an association between health care expenditure and mortality rates holds for all regressions except the one on suicide rates. This association is reinforced in models that take into account public-only health expenditure and its impact on older age groups. Government intervention in health seems to have no impact on infant mortality. Third, a strong protective effect of government-sponsored welfare expenditure on infant mortality was observed. This effect is weaker on other causes of death and suggests that older individuals, in this sample of developed countries, may have reached a stage of the epidemiological transition in which health improvement is indifferent to government assistance and may depend largely on behavioural change.

The remainder of this study is organised as follows: Section 2 provides a brief discussion on the determinants of health. Section 3 outlines the estimation methodology and presents the data and some relevant research questions. Section 4 presents and discusses the findings. The conclusion and implications for public social policies are drawn in Section 5.

\section{WHAT DO WE KNOW ABOUT THE DETERMINANTS OF HEALTH?}

\subsection{Health expenditure and health}

In most developed countries, life expectancy at all ages has been increasing for both males and females over the course of the past century. For much of this period, particularly over the decade of the 1950s and beyond, so too has spending on health (Folland et al. 2013). These two facts may, in some respects, point to the possibility that the returns from health spending have been positive for most if not all of this period. It is questionable, however, how much of these gains in life expectancy can be attributed to the expansion in health care, and years of research by health historians have left us with no shortage of answers. In an earlier view, which is mainly associated with the work of Thomas McKeown (1976), most of 
the improvements in life expectancy cannot be attributed to the medicalisation of health care because most of the effective medical interventions that could be used to improve or stabilise health were only available well after most of the advances preventing or attenuating major causes of death had occurred. Although this thesis continues to enjoy popularity, critics point out that McKeown overemphasised the role of income and social capital formation and completely ignored the tremendous influence advances in public health have had on improving health over the period from 1870 to about 1940 (Folland et al. 2013; Santerre - Neun 2010; Szreter 2000). Other critics argue that although McKeown's theoretical approach towards the understanding of mortality trends may have been well-suited for explaining reductions in infectious and nutritional diseases, it is less useful for explaining declines in chronic diseases, given that its underlying causes are not as clearly external to the individual as the causes of many contagious diseases (Schnittker - Karandinos 2010). It is plausible, instead, that an outgrowth of developments in science, technology and medicine became the driving engines of mortality decline over the past 70 years, especially novel medical treatments and pharmaceuticals (Bunker 2001).

How great has this influence been in determining improvements in health? Mackenbach (1996), for example, extended McKeown's model from the first half of the $20^{\text {th }}$ century to the second and concluded that the contribution of medical care to health was rather small prior to 1970 (less than 20 percent), but that it was much greater after that. Evidence of this increased sensitivity of health outcomes to investment in health care began accumulating after the 1960s and has continued up to the present day. For example, Auster et al. (1969) and Hadley (1982) estimated that a 10 percent increase in per capita health care expenditure led to a 1 percent and a 1.5 percent decrease in the age-adjusted mortality rate, respectively. In a more recent study that analyses the relationship between measures of inputs and outputs of health care systems for 175 countries, Jaba et al. (2014) showed a significant association between health expenditure and life expectancy. Equally important, studies that take into account the full spectrum of diseases with which health care deals demonstrate, with varying degrees of reliability, that spending on health has produced positive and significant benefits for particular conditions (see Gallet - Doucouliagos 2017 for a summary). There is also evidence that health care spending has a larger impact on health outcomes among non-OECD countries (which spend less on health care) than on OECD countries, where the additional benefits from more spending appear to be declining at the margin (McGuire 2005; Gupta et al. 2003). If this is indeed the case for developed countries, the determinants of marginal improvements in health must lie in the other factors associated with the production of health (Brainerd - Cutler 2005). 


\subsection{Other determinants and health}

Beyond the factors directly related to health care and medicine, an important body of research identified and shed light on the many pathways linking certain resources and conditions to health. For example, in a cross-national comparative analysis assessing whether and how social expenditure relates to health outcomes, Bradley and Taylor (2013) have provided evidence that levels of spending on social welfare programs, such as unemployment or old-age benefits, were associated with higher life expectancies, lower infant mortality rates and fewer potential years of life lost across the OECD. In a similar vein, Ferreira et al. (2019) and Minoiu and Andrés (2008) document a negative statistical association between social welfare expenditure and suicide, whereas Marmot et al. (2008) and Marmot and Wilkinson (2006) offer evidence that health improves at each step up the income and social hierarchy and that higher inequality levels are associated with worse health status. Questions remain, however, concerning effects resulting from temporary changes in the economy. For example, a long line of research reasons that economic downturns can actually improve many aspects of physical (not mental) health and reduce mortality risk (e.g., Ruhm 2015; Ionides et al. 2013; Kristjuhan - Taidre 2012). Unsurprisingly, it is also argued that higher levels of education are associated with physical and mental wellbeing (see Santerre - Neun 2010, for a summary). On this relationship, Cutler and Lleras-Muney (2006) estimate increases in life expectancy by between 0.18 and 0.6 years for every additional year of formal education. Other evidence suggests that population health status may be much more sensitive to lifestyle and environmental factors than previously thought. For example, the work of Balia and Jones (2008) has shown that lifestyle, particularly smoking and sleep patterns, are key predictors of mortality rates, and Cummins et al. (2005) identified features of neighbourhood social and physical environments that were predictive of poor health. Age and marital status are other variables found to be worth consideration (Santerre - Neun 2010). In this regard, for example, Marmot et al. (2000) found the mortality rate of married women to be lower than their single counterparts in a sample of Israeli adult women, and empirical evidence provided by Kravdal (2001) indicated that married women have a higher probability of survival for 12 common forms of cancer in Norway than unmarried women. 


\section{RESEARCH QUESTIONS, DATAAND EMPIRICAL STRATEGY}

\subsection{Research questions}

In this study, we further explored the relationships raised by the literature and assess whether health, socio-economic, life-style, and public policy variables are still relevant contextual factors across the OECD. To explore these relationships, this study focuses on the following research questions: (i) does health care expenditure still have a demonstrable impact on objective assessments of health, such as all-cause and cause-specific mortality rates; (ii) if so, is it an effect of the level of effort exerted by national governments in providing health services and improving the health level of populations; or (iii) are improvements in numbers and rates of these measures of population health a reflection of a multitude of factors, such as social welfare protection, income, lifestyle and environment, that may affect outcomes?

\subsection{Data}

Information on mortality rates is one of the few exceptions to the lack of consistent time series for health measures across countries. Thus, we address the first question using data for a sample of OECD countries over the 1995-2015 period for five health measures - total deaths from all causes, total deaths from ischemic heart diseases, total deaths from malignant neoplasms, total deaths from suicide and self-inflicted injury and total deaths during infancy - and aggregate mortality equations that include data extracted from WHO Mortality Database and OECD Health Statistics. Total deaths from all causes, ischemic heart diseases, malignant neoplasms and suicide and self-inflicted injury are measured as age-standardised mortality rates (SDR) per 100,000 individuals. Infant mortality is measured as total deaths during infancy per 1,000 live births. We focus on cause-specific mortality rates because of their usefulness in providing us with knowledge of mortality differences over time or space, as well as important clues about the social and epidemiologic pathways that affect population mortality. We note, however, that attributions of cause of death in most high-income countries still have inherent imprecision. In specifying our baseline models, we draw on the health economics literature and propose that the processes underlying the health measures mentioned above are functions of health care services, income growth, female labour force participation, percentage of urban population, alcohol consumption and technological innovation-standard indicators that are intended to capture a number of possible effects. These variables, notations and their sources are summarized in Table 1. 
Table 1. Variables, notation and their sources

\begin{tabular}{|c|c|c|}
\hline Variables & $\begin{array}{c}\text { Notation } \\
\text { (models in parentheses) }\end{array}$ & Source \\
\hline \multicolumn{3}{|l|}{ Dependent variables: } \\
\hline M (ln of SDR, all causes, all ages, per 100000 inhabitants) & $\operatorname{LnM}(1$ and 6$)$ & 1 \\
\hline $\begin{array}{l}\text { IHD (ln of SDR, ischemic heart disease, all ages, } \\
\text { per 100,000 inhabitants) }\end{array}$ & $\ln I H D(2$ and 7$)$ & 1 \\
\hline $\begin{array}{l}\text { MN (ln of SDR, malignant neoplasms, all ages, } \\
\text { per 100,000 inhabitants) }\end{array}$ & $\ln M N(3$ and 8$)$ & 1 \\
\hline $\begin{array}{l}\text { SSII (ln of SDR, suicide and self-inflicted injury, } \\
\text { per 100,000 males }\end{array}$ & $\ln \operatorname{SSII}(4$ and 9) & 1 \\
\hline $\begin{array}{l}\text { IMR (ln of IMR, infant mortality rate, } \\
\text { deaths per 1,000 live births) }\end{array}$ & $\ln I M R$ (5 and 10$)$ & 2 \\
\hline \multicolumn{3}{|l|}{ Independent variables } \\
\hline $\begin{array}{l}\text { Ln of real per capita total expenditure on health - lagged } \\
\text { (at constant PPPs in } 2010 \text { US\$) }\end{array}$ & $\ln T H E$ & 2 \\
\hline $\begin{array}{l}\text { Ln of real per capita public expenditures on health - } \\
\text { lagged (at constant PPPs in } 2010 \text { US\$) }\end{array}$ & $\ln P H E$ & 2 \\
\hline $\begin{array}{l}\text { Ln of real per capita public social welfare expenditures - } \\
\text { lagged (at constant PPPs in } 2010 \text { US\$) }\end{array}$ & $\ln S W E$ & 2 \\
\hline Ln of per capita alcohol consumption (age $15+$ ) & $\ln A L C$ & 2 \\
\hline $\begin{array}{l}\text { Real per capita GDP growth (annual percentage growth } \\
\text { rate based on constant local currency) }\end{array}$ & $G D P G$ & 3 \\
\hline $\begin{array}{l}\text { Labor force participation rate, female } \\
\text { (percentage of female population ages 15-64) }\end{array}$ & FLFP & 3 \\
\hline Urban population (percentage of total population) & $U R B$ & 3 \\
\hline
\end{tabular}

Data sources: 1. World Health Organization (2018b); 2. OECD (2018); 3. World Bank (2018).

To answer the remaining questions, we then modify and extend the health production function, as defined by Auster, Leveson and Sarachek (1969), by incorporating measures that represent national governments' involvement in the health care and social welfare protection sectors. As countries differ in both how they track spending on public health or social welfare programs and how they classify these spending categories, total and public health expenditure data were taken from the OECD Health Data 2018 edition and serve as a proxy for the amount of health service availability, as well as the overall quality of health systems. Similarly, expenditure data in the domain of public social welfare services were collected from the OECD Social Expenditure Statistics 2018 edition. This variable measures the financial effort national governments made to address the needs of households and individuals during circumstances that adversely affected their welfare and is indicative of the level of social fairness that a given country intends to attain. This, in turn, will affect levels of life satisfaction and thus health outcomes. In this setting, by comparing mortality from causes when a short-term 
relationship between health and social welfare spending is unexpected, such as from most cancers and ischemic heart diseases, with mortality from diseases when changes are expected with spending, such as infant deaths and suicides, this analytical framework can indirectly assess which aspects of population mortality are more sensitive to spending on social welfare support than on health care. Data related to other control variables were collected from the World Bank (2018) World Development Indicators database.

\subsection{Empirical strategy and sample characteristics}

In quantifying the relationship between the health measures mentioned above and factors amenable to population health in the OECD, we retain in our data set only the observational units for which we have data on all variables of interest and for most years (Austria, Canada, Denmark, Finland, France, Germany, Greece, Ireland, Israel, Italy, Japan, Netherlands, Norway, Portugal, Spain, United Kingdom, United States). The final data set was an unbalanced panel with 17 cross-sectional units and 303 observations.

To provide information about the degree of association between the variables used in the investigation, we employed a standard panel regression approach and a fixed-effects transformation of the data through which the effects that were specific to a particular country and did not vary over time were captured. Thus, with the country representing the unit of our analysis, the production function of these measures of health can be specified by the following parsimonious model (five variants of which we implement):

$$
\begin{gathered}
\ln M_{i t}=a_{i}+\beta_{l} \ln H E_{i t-1}+\beta_{2} \ln A l c_{i t}+\beta_{3} G D P G_{i t-1}+\beta_{4} F L F P_{i t}+\beta_{5} U R B_{i t}+ \\
\beta_{6} \text { Time }+u_{t}
\end{gathered}
$$

Equation 1 relates the (natural) log of mortality $(M)$, by country and year, to the $\log$ of the past (or present) values of per capita health expenditure $(H E)$, the log of per capita alcohol consumption ( $A l c)$, income growth $(G D P G)$, the female labour force participation rate $(F L F P)$, the percentage of population that is urbanised $(U R B)$, a time trend (Time) and the observation-specific error term $(u)$. To improve the regression models, the log transformation was not applied to percentages, and some of the variables considered in the analysis are introduced in oneperiod lagged form (namely, $H E_{i t-1}$ and $G D P G_{i t-1}$ ). This is justified by the presence of two key considerations: (i) the fact that the influence of mortality patterns of economic and other variables is usually not contemporaneous, but the result of period(s) of exposure and (ii) the need to ensure that we are measuring the effect of expenditure on mortality rather than the effect of mortality on expenditure. For 
purposes of accuracy, per capita figures are used for the health expenditure (HE) and alcohol consumption $(A l c)$ terms because these are considered better indices of change in individual welfare. Also, an iterative AR(1) procedure for correcting for serial correlation and White's (1980) method for obtaining heteroscedasticitycorrected regression results was applied to all specifications. As a final application, panel unit root tests developed by Levin, Lin and Chu (2002) were used to ensure that the variables included in all specifications were free of any unit root processes. The test results indicated that there was no sufficient evidence pointing to the acceptance of the (null) hypothesis that all series in the panel are non-stationary and that the series was generated by stationary or approximately stationary processes. Regressions were performed by means of the EViews (version 9.0) statistical software.

\section{ESTIMATION RESULTS AND DISCUSSION}

The first set of detailed results is presented in Table 2 (Models 1 through 5). With the exception of the regression using the suicide rate as a dependent variable (Model 4), these show that some of the explanatory variables of interest significantly affect mortality rates (e.g., the time trend variable, the percentage of population that is urbanised, the alcohol consumption and health care), as hypothesised earlier. However, the statistical significance, sign and coefficient magnitudes for this set of explanatory variables showed strong differences with respect to age and the cause of death. Notably, greater population density was likely to impose greater health hazards in urban environments and lead to higher mortality rates. The effect sizes and statistical significance were larger in percentage terms for the leading causes of death (i.e., ischemic heart disease and malignant neoplasms) than for all-cause mortality. This finding might reflect the effect of an omitted variable, such as carbon dioxide emissions and stress levels, which is expected to be positively correlated with the above-mentioned causes of death and the urbanisation rate. For children, a weak negative relationship between urbanisation rates and mortality was obtained and hinted at some important differences in the underlying stochastic process, describing age-specific mortality rates. In considering the other variables included in Table 2, only in the case of Model 5 did we find that a higher female labour force participation rate was significantly associated with a lower mortality rate. For this (younger) age group, the increased benefits that might result when women enter the labour force more than offset the possible adverse effects of having mothers not devoting the bulk of their time to rearing their young children. 
A similar pattern emerged for the per capita real income growth variable. Here, the coefficients on this proxy for economic conditions were statistically significant in Models 2 and 5 and negative in all regressions in Table 2 except the one on infant mortality rates. Based on the findings of this study, a 1 percent increase in the per capita real income growth variable would be expected to reduce deaths from ischemic heart diseases by approximately 0.0015 percent and raise infant deaths by approximately 0.0032 percent. Paradoxically, the positive relationship between economic growth and infant mortality was consistent with empirical evidence, suggesting that infant deaths decrease when the economy weakens (Dehejia - Lleras-Muney 2004; Ruhm 2000). In turn, although alcohol consumption appeared to have some negative effects on mortality (i.e., Table 2 reveals that this lifestyle risk factor was positive and significantly correlated to all-cause mortality), its effects were insignificant in regressions explaining the specific causes of death (Models 2, 3, 4 and 5). To some extent, this result offers some evidence to support the medical argument that alcohol consumption might have some beneficial effects in reducing mortality due to, for example, ischemic heart diseases and cancer (Emberson - Bennett 2006; Barefoot et al. 2002).

Furthermore, the findings imply that mortality rates have decreased over time, perhaps reflecting the growth of health-enhancing knowledge and technologies in this sample of countries. The coefficients on the trend variable were negative and statistically significant in all regressions except the ones on suicide rates, thus raising the possibility that the underlying stochastic processes describing mental and physical health may not be the same. More important, when socioeconomic, demographic and lifestyle factors were taken into account, the empirical results indicated that greater quantities of health care led to decreases in mortality rates.

As shown in Table 2, the coefficients on the health expenditure term were negative in all regressions and statistically insignificant only in the model for suicide and self-inflicted injury (Model 4). Specifically, a one percentage point increase in per capita real health care expenditure was associated with a 0.07 percent decrease in all-cause mortality in the subsequent year. This link seemed to be stronger and more robust in Models 2 and 3, which looked at mortality rates from ischemic heart diseases and malignant neoplasms - a finding that was in accordance with the empirical literature. Ford et al. (2007), for example, estimated that nearly half of the decline in U.S. mortality from heart diseases was due to evidence-based medical therapies, and Potts and Schwartz (2004) identified cancer as one of an array of conditions that could now be treated effectively with innovative medical interventions and newer-vintage pharmaceuticals. In the regression using the infant mortality rate as a dependent variable (Model 5), the estimated coefficient was negative but only significant at the 10 percent level. Because infant mortality and low birth weight are important markers of unhealthy 
Table 2. Fixed effects estimates of all-cause and cause-specific mortality equations (standard errors in parenthesis)

\begin{tabular}{l|c|c|c|c|c}
\hline & Model 1 & Model 2 & Model 3 & Model 4 & Model 5 \\
\hline Dep. Variable & $\operatorname{lnM}$ & $\operatorname{lnIHD}$ & $\operatorname{lnMN}$ & $\operatorname{lnSSII}$ & $\operatorname{lnIM}$ \\
\hline Ind. Variables & Coefficients & Coefficients & Coefficients & Coefficients & Coefficients \\
\hline Constant & & & & & \\
& $6.567111^{*}$ & $4.667439^{*}$ & $4.962386^{*}$ & $2.801806^{* *}$ & $3.797619^{* *}$ \\
lnTHE - lagged & $(0.324511)$ & $(0.526093)$ & $(0.179897)$ & $(1.470619)$ & $(0.827484)$ \\
& $-0.067795^{* * *}$ & $-0.189505^{*}$ & $-0.051671^{* *}$ & -0.239467 & $-0.127001^{* * *}$ \\
GDPG - lagged & $(0.039673)$ & $(0.045145)$ & $(0.023898)$ & $(0.153493)$ & $(0.075676)$ \\
& -0.000398 & $-0.001461^{*}$ & -0.000317 & -0.002341 & $0.003232^{*}$ \\
FLFP & $(0.000461)$ & $(0.000536)$ & $(0.000471)$ & $(0.001941)$ & $(0.001129)$ \\
& -0.000618 & $0.004799^{* * *}$ & 0.000745 & -0.000173 & $-0.010926^{*}$ \\
URB & $(0.001237)$ & $(0.002976)$ & $(0.001079)$ & $(0.006274)$ & $(0.003588)$ \\
& $0.002942^{* * *}$ & $0.015055^{* *}$ & $0.004287^{*}$ & 0.016799 & -0.003863 \\
lnALC & $(0.001718)$ & $(0.007088)$ & $(0.001188)$ & $(0.012530)$ & $(0.004524)$ \\
& $0.056397^{* *}$ & 0.056772 & 0.026153 & 0.038544 & -0.075938 \\
Time Trend & $(0.027594)$ & $(0.050848)$ & $(0.025323)$ & $(0.151158)$ & $(0.097443)$ \\
& $-0.020085^{*}$ & $-0.058684^{*}$ & $-0.012560^{*}$ & -0.005500 & $-0.019988^{*}$ \\
AR(1) & $(0.001621)$ & $(0.006958)$ & $(0.000681)$ & $(0.006203)$ & $(0.003125)$ \\
& $0.730018^{*}$ & $0.896844^{*}$ & $0.637276^{*}$ & $0.755266^{*}$ & $0.601025^{*}$ \\
& $(0.063480)$ & $(0.038574)$ & $(0.070391)$ & $(0.068665)$ & $(0.069029)$ \\
\hline Number of obs. & 310 & 310 & 310 & 310 & 310 \\
Number of cross- & 17 & 17 & 17 & 17 & 17 \\
sections & 0.986141 & 0.995432 & 0.983581 & 0.978566 & 0.946013 \\
R Square & 0.985026 & 0.995058 & 0.982261 & 0.976842 & 0.941717 \\
Adj. R Square & 0.018534 & 0.033795 & 0.014792 & 0.071941 & 0.067668 \\
S. E. of regression & $884.7736^{*}$ & $2662.244^{*}$ & $744.9125^{*}$ & $567.7011^{*}$ & $220.1814^{*}$ \\
F statistic & 2.231699 & 2.245651 & 2.471908 & 1.964767 & 2.326479 \\
D W Statistic & & & & & \\
\hline
\end{tabular}

Note: * significant at $1 \%$; ** significant at $5 \%$; *** significant at $10 \%$.

postnatal conditions and both are, in turn, influenced by maternal characteristics (e.g., health-related behaviours, access to health care, maternal education, marital and family status and household and family conditions), this result could be traced back to both individual and contextual factors for this age group (Palloni - Yonker 2012).

So far, the analysis presented in Table 2 treats health care expenditure as a single entity of funds. In Table 3, we explored whether public funding of health care expenditure mattered for the selected measures of health while adding public welfare expenditure as a control variable for the level of effort exerted by national governments to provide financial support for individuals and households in disadvantaged circumstances. On this account, we disaggregated public social expenditure, as defined and collected by the OECD, into its social welfare and health components. The empirical results suggested that government involvement in health care had no impact on all-cause mortality (Model 6), because the 
estimated coefficient on the government variable was not statistically different from zero at conventional levels of significance. However, except for the regression using the infant mortality rate as a dependent variable (Model 10), the results clearly showed a strong negative association between public expenditure on health care and cause-specific mortality rates (Models 7, 8 and 9). It is in fact remarkable that this public policy variable was the sole explanatory variable that was statistically significant in the model explaining suicide rates (Model 9). Specifically, an increase in public health care outlays by 1 percentage point would lead to $0.144,0.054$ and 0.314 percent reductions in mortality from ischemic heart diseases, malignant neoplasms and suicide and self-inflicted injury mortality rates in the subsequent year.

The statistically significant results for the public health expenditure term suggested that many public health systems and services were providing timely and effective care to people most in need of assistance. Moreover, given that its coefficient's magnitude was higher for deaths from suicide and self-inflicted injury than for deaths from ischemic heart diseases and malignant neoplasms, our estimates in Model 9 suggested that public investment in the prevention and treatment of mental illness and the promotion of mental health could significantly and effectively mitigate some of the mental health consequences of personal crises. In the case of Model 10, the public welfare expenditure term was the sole public policy variable that was significantly associated with infant mortality rates. For this age group, a one percentage point increase in public welfare expenditure would lead to a reduction in infant mortality rates by 0.153 percent. This result could suggest critical directions for improvement by emphasising the importance of social policy solutions that target young children and their immediate family and that current child-health outcomes may suffer from inadequate public intervention in health care. In the remaining explanatory variables, we noted that the inclusion of the public policy variables did not significantly alter the results presented in Table 3.

\section{CONCLUSION AND IMPLICATIONS FOR PUBLIC SOCIAL POLICIES}

As previous studies have shown, there appears to be a relationship between health care services provision and various measures of population health, but extra spending, for a variety of reasons, may not benefit disease outcomes (Jones 2002; Wang 2002; Or 2000). Thus, in this study, we started by raising the questions of whether the financial inputs in health care services are only one of a number of factors determining population mortality and, most importantly, whether the significant contribution of health care to health in the recent past is now dimin- 
Table 3. Fixed effects estimates of all-cause and cause-specific mortality equations (standard errors in parenthesis)

\begin{tabular}{l|c|c|c|c|c}
\hline & Model 6 & Model 7 & Model 8 & Model 9 & Model 10 \\
\hline Dep. Variable & $\operatorname{lnM}$ & $\operatorname{lnIHD}$ & $\operatorname{lnMN}$ & $\operatorname{lnSSII}$ & $\ln$ IM \\
\hline Ind. Variables & Coefficients & Coefficients & Coefficients & Coefficients & Coefficients \\
\hline Constant & & & & & \\
& $6.787792^{*}$ & $4.171796^{*}$ & $4.515317^{*}$ & 2.115979 & $4.545002^{*}$ \\
lnPHE - lagged & $(0.429022)$ & $(0.786581)$ & $(0.368684)$ & $(1.741907)$ & $(0.854680)$ \\
& -0.042339 & $-0.144071^{*}$ & $-0.054082^{*}$ & $-0.314299^{* * *}$ & -0.056394 \\
lnSWE - lagged & $(0.031543)$ & $(0.040301)$ & $(0.018382)$ & $(0.167008)$ & $(0.100853)$ \\
& -0.046517 & 0.010239 & 0.052312 & 0.116077 & $-0.153367^{* *}$ \\
GDPG - lagged & $(0.053067)$ & $(0.084444)$ & $(0.052273)$ & $(0.176875)$ & $(0.069972)$ \\
& -0.000639 & $-0.001599^{*}$ & -0.000253 & -0.002860 & $-0.002533^{* *}$ \\
FLFP & $(.000537)$ & $(0.000651)$ & $(0.000469)$ & $(0.001884)$ & $(0.001264)$ \\
& -0.000889 & 0.005008 & 0.000724 & 0.000259 & $-0.011532^{*}$ \\
URB & $(0.001718)$ & $(0.003295)$ & $(0.001101)$ & $(0.005787)$ & $(0.003369)$ \\
& 0.002605 & $0.014585^{* *}$ & $0.004088^{*}$ & 0.017919 & -0.002831 \\
lnALC & $(0.001843)$ & $(0.007277)$ & $(0.001159)$ & $(0.011625)$ & $(0.004497)$ \\
& $0.055800^{* *}$ & 0.060282 & $0.035628^{* * *}$ & 0.064890 & -0.108762 \\
Time Trend & $(0.027058)$ & $(0.049743)$ & $(0.022069)$ & $(0.147814)$ & $(0.101571)$ \\
& $-0.019914^{*}$ & $-0.059619^{*}$ & $-0.013387^{*}$ & -0.006286 & $-0.018645^{*}$ \\
AR(1) & $(0.001792)$ & $(0.007332)$ & $(0.000957)$ & $(0.006189)$ & $(0.003542)$ \\
& $0.722140^{*}$ & $0.894472^{*}$ & $0.625607^{*}$ & $0.743346^{*}$ & $0.566592^{*}$ \\
& $(0.063814)$ & $(0.039534)$ & $(0.064125)$ & $(0.072615)$ & $(0.062371)$ \\
\hline Number of obs. & 305 & 305 & 305 & 305 & 305 \\
Number of cross- & 17 & 17 & 17 & 17 & 17 \\
sections & 0.986106 & 0.995390 & 0.983292 & 0.979130 & 0.945650 \\
R Square & 0.984915 & 0.994995 & 0.981859 & 0.977341 & 0.941008 \\
Adj. R Square & 0.018395 & 0.034008 & 0.014761 & 0.071522 & 0.066493 \\
S. E. of regression & $827.9986 *$ & $2519.322^{*}$ & $686.5824^{*}$ & $547.3469^{*}$ & $203.7166^{*}$ \\
F statistic & 2.285295 & 2.246798 & 2.440933 & 1.939880 & 2.272339 \\
D W Statistic & & & & & \\
\hline
\end{tabular}

Note: * significant at $1 \%$; ** significant at $5 \%$; *** significant at $10 \%$.

ishing. In addressing these and related questions, we focused on fixed-effects regressions, using data for 17 OECD countries for the past two decades (1995 to 2015), as reported in Table 2. This table shows the results for five alternative model estimations, using deaths from all causes and deaths from a spectrum of diseases as dependent variables, while controlling for lifestyle factors, environmental surroundings, socioeconomic status and the state of medical technology. The results for the five econometric specifications (Models 1 through 5) suggest critical directions for improvement by identifying what strengthens and weakens key aspects of population health. In relation to control variables, for example, the basic (all-cause mortality) model specification suggests that increased income has a negative effect on mortality rates and that urbanised environments and alcohol consumption are considered to be important health risk factors. Also, this positive 
effect is observed on two of the four causes of death examined in Table 2, namely, deaths from ischemic heart diseases and malignant neoplasms, but the statistically significant coefficients disappear for the alcohol consumption variable.

The findings also indicate that increased income adversely affects infant health and higher female labour force participation causes infant mortality to decline. In describing our findings for the health expenditure term, with varying degrees of magnitude and reliability, the results provide evidence that timely and effective medical interventions have played a significant role in the production of life gains, particularly for disease-states that are associated with the high prevalence of chronic illnesses. Moreover, given the low explanatory power of the included health expenditure terms for infant and suicide mortality rates, we conclude that illnesses that affect older adults and physical health are more responsive to general health care interventions, as opposed to diseases that occur early in the lifecourse or affect the mental health of individuals and populations.

Public policies can also play important roles in shaping key aspects of health. Hence, in Table 3, we restricted the coefficients on the health expenditure term to public-only spending and incorporated public welfare expenditure into the analysis. There are several reasons for including both measures of policy intervention in our specifications. First, available data on public spending are more robust than those on private spending. Second, in most developed countries, health and welfare protection are major functions of national governments. Third, given society's limited resources, it is important to know which factors have positive marginal contributions to health so that least-cost policies can be designed. In looking at the results, we found that the effect of removing private contributions to health care expenditure strengthened the association between investments and benefits to the measures of health mentioned above. We note that greater government intervention in health care is significantly associated with a reduction in the rates of suicide, deaths from heart diseases and deaths from malignant neoplasms and is further evidence that shifting the spending balance towards public health expenditure is beneficial for these aspects of health. Thus, public health solutions that target middle-aged and older adults (such as, for example, policy initiatives designed to ensure that the bulk of those waiting for care experience short waits) can substantially deliver health gains and may increase disability-free life expectancy as well as reduce a wide range of economic and personal/psychologic costs (Dixon et al. 2004).

However, the empirical results also imply that government involvement in health care has no impact on infant mortality and that benefits on government health spending can be achieved more effectively by social policy solutions that provide children and families with the support necessary to maintain positive mental and physical well-being. Such policy solutions may emphasise the im- 
portance of reducing disparities in access to good-quality antenatal and postnatal health care; the importance of promoting positive early childhood development (such as providing subsidised parental leave in the first year of life); and the importance of providing good-quality child care and preschool education. Moreover, given that adolescent mortality now exceeds infant and early-childhood mortality in most developed countries, the continued reduction of inequalities across the social gradient in health may also require a sustained commitment by national governments to policy solutions that target adolescents and young adults. This makes intuitive and economic sense because a health disadvantage early in the life-course can lead to life-long consequences for everyone. Among the remaining causes of death, the effect of social welfare expenditure on mortality appears to be zero in our estimations. One proposed explanation for this important difference in the stochastic process underlying cause-specific mortality rates is that some categories of social welfare expenditure (such as spending related to family support programs, old-age pensions and survivors' benefits, housing subsidies, unemployment benefits, active labour market programs, or support for people with disabilities) may have stronger associations with the health outcomes mentioned above than others (Bradley et al. 2011; Marmot - Wilkinson 2005).

Overall, the results from this study raise issues of political feasibility and policy context by suggesting that the balance between health and social welfare expenditure in countries is related to their health outcomes and that the strength of this association may differ depending on the source of funding (i.e., private vs. public) and on the type of social program. These findings raise new questions for further research, some of which are driven by limitations in the study's scope. First, as discussed above, we chose to use mortality rates as indicators of health because these are measures of health that are reliable, stable over time, and equivalent across settings. Although these traditional measures of health may have been used for decades to measure burden and to compare the impact of diseases, reliance on this single set of dependent variables may not fully assess several meaningful aspects of health status, such as, for example, a reduction in pain and discomfort and other improvements in the quality of life. It is often the case, however, that on these summary measures where personal assessment of health or perceived quality of life are used, data may not be readily available and/ or reliable. Second, in order to better understand how both areas of government intervention affect traditional measures of health, this field of study could be deepened by further exploring variations in the balance between mortality rates and social welfare spending across countries. Third, and before these findings are allowed to sway expenditure decisions, future inquiries must provide evidence on the relationship between specific categories of social welfare expenditure and specific measures of health. If, for example, social welfare spending is in fact 
associated with better health outcomes among adults, it might be expected that social welfare programs that target latter stages of life would be most influential. Fourth, with governments in most OECD countries taking a broader view of setting limits to spending, the role and possible effects of an increasing reliance on private rather than public funding of health and social welfare protection merits further examination. Finally, when lack of accuracy and availability does not impose limitations on the use of expenditure data in the analysis of welfare states and social policy, future research must address the exploratory research questions of our study by including more countries (i.e., OECD and non-OECD countries), incorporating additional health indicators, extending the years under consideration and, when possible, looking at trends within individual countries.

\section{REFERENCES}

Auster, R. - Leveson, I. - Sarachek, D. (1969): The Production of Health, an Exploratory Study. Journal of Human Resources 4(4): 411-436.

Balia, S. - Jones, A. (2008): Mortality, Life-Style, and Socio-Economic Status. Journal of Health Economics 27: 1-26.

Barefoot, J. - Morten Grønbæk, J. - Feaganes, R. - McPherson, R. - Williams, I. - Siegler, C. (2002): Alcoholic Beverage Preference, Diet, and Health Habits in the UNC, Alumni Heart Study. American Journal of Clinical Nutrition 76: 466-472.

Bradley, E. -Taylor, L. (2013): The American Paradox: Why Spending More Is Getting Us Less. Philadelphia: Public Affairs.

Bradley, E. - Elkins, B. - Herrin, J. - Elbel, B. (2011): Health and Social Services Expenditures: Associations with Health Outcomes. BMJ Quality and Safety 20(10): 826-831.

Brainerd, E. - Cutler, D. (2005): Autopsy on an Empire: Understanding Mortality in Russia and the Former Soviet Union. Journal of Economic Perspectives 19: 107-130.

Bunker, J. (2001): Medicine Matters after All: Measuring the Benefits of Medical Care, a Healthy Lifestyle, and a Just Social Environment. London: The Nuffield Trust.

Cummins, S. - Stafford, M. - Macintyre, S. et al. (2005): Neighborhood Environment and Its Association with Self-Rated Health: Evidence from Scotland and England. Journal of Epidemiology and Community Health 59: 207-213.

Cutler, D. - Deaton, A. - Lleras-Muney, A. (2006); The Determinants of Mortality. Journal of Economic Perspectives 20(3): 97.

Dehejia, R. - Lleras-Muney, A. (2004): Booms, Busts, and Babies' Health. Quarterly Journal of Economics 119(3): 1091-1130.

Dixon, J. - Lewis, R. - Rosen, R. - Finlayson, B. - Gray, D. (2004): Managing Chronic Disease: What can We Learn from the US Experience. London: King's Fund.

Emberson, J. - Bennett, D. (2006): Effect of Alcohol on Risk of Coronary Heart Disease and Stroke: Causality, Bias, or a Bit of Both? Vascular Health Risk Management 2(3): 239-249.

Ferreira, E. - Monteiro, J. - Manso, J. (2018): Are Economic Crises Age and Gender Neutral? Evidence from European Union Mortality Data. Economic Analysis and Policy 60: 69-77. 
Ferreira, E. - Monteiro, J. - Manso, J. (2019): "Death by Economic Crisis”: Suicide and SelfInflicted Injury in the European Union (EU15) during the Worst of Times. Society and Economy 41(1): 145-164.

Folland, S. - Goodman, A. - Stano, M. (2013): The Economics of Health and Health Care. Upper Saddle River, New Jersey: Pearson Education Inc.

Ford, E. - Ajani, U. - Croft, J. - Critchley, J. - Labarthe, D. - Kottke, T. - Giles, W. - Capewell, S. (2007): Explaining the Decrease in U.S. Deaths from Coronary Disease, 1980-2000. The New England Journal of Medicine 356: 2388-2398.

Gallet, C. - Doucouliagos, H. (2017): The Impact of Health Care Spending on Health Outcomes: A Meta-Regression Analysis. Social Science \& Medicine 179: 9-17.

Gupta, S. - Verhoeven, M. - Tiongson, E. (2003): Public Spending on Health Care and the Poor. Health Economics 12(8): 685-696.

Hadley, J. (1982): More Medical Care, Better Health. Washington, D.C.: Urban Institute Press.

Ionides, E. - Wang, Z. - Tapia-Granados, J. (2013): Macroeconomic Effects of Mortality Revealed by Panel Analysis with Nonlinear Trends. Annals of Applied Statistics 7(3): 1362-1385.

Jaba, E. - Balan, C. - Robu, I. (2014): The Relationship between Life Expectancy at Birth and Health Expenditures Estimated by a Cross-Country and Time-Series Analysis. Procedia Econonics and Finance 15: 108-114.

Jones, C. (2002): Why have Health Expenditures as a Share of GDP Risen So Much? NBER Working Paper No. 9325.

Kravdal, O. (2001): The Impact of Marital Status on Cancer. Social Science and Medicine 52: 357-368.

Kristjuhan, U. - Taidre, E. (2012): The Last Recession Was Good for Life Expectancy. Rejuvenation Research 15: 134-135.

Levin, A. - Lin, C. - Chu, C. (2002): Unit Root Tests in Panel Data: Asymptotic and Finite Sample Properties. Journal of Econometrics 108: 1-24.

Mackenbach, J. (1996): The Contribution of Medical Care to Mortality Decline: McKeown Revisited. Journal of Clinical Epidemiology 49(11): 1207-1213.

MacKeown, T. (1976): The Role of Medicine: Dream, Mirage, Or Nemesis. London: Nuffield Provincial Hospitals Trust.

Marmot, M. (2000): A Social View of Health and Disease. In: Heller, T. - Muston, R. - Sidell, M. - Lloyd, C. (eds): Working for Health. London: Sage Publications.

Marmot, M. - Wilkinson, R. (2006): Social Determinants of Health. Oxford: Oxford University Press.

Marmot, M. - Friel, S. - Bell, R. - Howeling, A. - Taylor, S. (2008): Closing the Gap in a Generation: Health Equity through Action on the Social Determinants of Health. Lancet 372: 16611669.

McGuire, J. (2005): Basic Health Care Provision and Under-5 Mortality: A Cross-National Study of Developing Countries. World Development 34(3): 405-425.

Minoiu, C. - Andrés, A. (2008): The Effect of Public Spending on Suicide: Evidence from US State Data. The Journal of Socio-Economics 237-261.

OECD (2018): OECD.Stat. https://stats.oecd.org/Index.aspx?DataSetCode=SOCX_AGG, accessed 05/01/2018.

Or, Z. (2000): Determinants of Health Outcomes in Industrialized Countries: A Pooled, CrossCountry, Time-Series Analysis. OECD Economic Studies 30: 53-77.

Palloni, A. - Yonker, J. (2012): Health in the U.S. at Young Ages: Preliminary Findings. OCDE Working Paper 2012-04. 
Potts, J. - Schwartz, W. (2004): The Impact of the Revolution in Biomedical Research in Life Expectancy by 2050. In: Aaron, H. J. - Schwartz, W. B. (eds): Coping with Methuselah: The Impact of Molecular Biology on Medicine and Society. Washington D. C.: Brookings Institution Press, pp. 16-25.

Ruhm, C. (2000): Are Recessions Good for Your Health? Quarterly Journal of Economics 115: 617-650.

Ruhm, C. (2015): Recessions, Healthy No More? Journal Health Economics 42: 17-28.

Santerre, R. - Neum, S. (2010): Health Economics: Theories, Insights, and Industry Studies. Mason: South-Western Cengage Learning.

Schnittker, J. - Karandinos, G. (2010): Methusela’s Medicine: Pharmaceutical Innovation and Mortality in the United States, 1960-2000. Social Science and Medicine 70: 961-968.

Szreter, S. (2000): The McKeown Thesis. Journal of Health Services Research and Policy 5(2): $119-121$.

Wang, L. (2002): Health Outcomes in Low-Income Countries and Policy Implications: Empirical Findings from Demographic and Health Surveys. World Bank Working paper No. 2831.

White, H. (1980): A Heteroscedasticity-Consistent Covariance Matrix Estimator and a Direct Test for Heteroscedasticity. Econometrica 48: 817-838.

World Bank (2018): World Development Indicators. https://data.worldbank.org/indicator, accessed $06 / 01 / 2018$.

World Health Organization (2018a): WHO Mortality Database. http://apps.who.int/healthinfo/ statistics/mortality/whodpms/, accessed 06/01/2018.

World Health Organization (2018b): Health for All Database. https://gateway.euro.who.int/en/ datasets/european-health-for-all-database/, accessed 06/01/2018.

Open Access. This is an open-access article distributed under the terms of the Creative Commons Attribution-NonCommercial 4.0 International License (https://creativecommons. org/licenses/by-nc/4.0/), which permits unrestricted use, distribution, and reproduction in any medium for non-commercial purposes, provided the original author and source are credited, a link to the CC License is provided, and changes - if any - are indicated. 